\title{
Lipid and Fatty Acid Composition of Diatoms Revisited: Rapid Wound-Activated Change of Food Quality Parameters Influences Herbivorous Copepod Reproductive Success
}

\author{
Thomas Wichard, ${ }^{[a, c]}$ Andrea Gerecht, ${ }^{[\mathrm{d}]}$ Maarten Boersma, ${ }^{[\mathrm{d}, \mathrm{e}]}$ Serge A. Poulet, ${ }^{[\mathrm{f}]}$ \\ Karen Wiltshire, ${ }^{[d]}$ and Georg Pohnert* ${ }^{* a, b]}$
}

\begin{abstract}
Lipid and fatty acid composition are considered to be key parameters that determine the nutritive quality of phytoplankton diets for zooplanktonic herbivores. The fitness, reproduction and physiology of the grazers are influenced by these factors. The trophic transfer of lipids and fatty acids from algal cells has been typically studied by using simple extraction and quantification approaches, which, as we argue here, do not reflect the actual situation in the plankton. We show that cell disruption, as it occurs during a predator's grazing on diatoms can drastically change the lipid and fatty acid content of the food. In some algae, a rapid depletion of polyunsaturated fatty acids (PUFAs) is observed within the first minutes after cell disruption. This fatty acid deple-
\end{abstract}

tion is directly linked to the production of PUFA-derived polyunsaturated aldehydes (PUA); these are molecules that are thought to be involved in the chemical defence of the algae. PUA-releasing diatoms are even capable of transforming lipids from other sources if these are available in the vicinity of the wounded cells. Fluorescent staining reveals that the enzymes involved in lipid transformation are active in the foregut of copepods, and therefore link the depletion processes directly to food uptake. Incubation experiments with the calanoid copepod Temora longicornis showed that PUFA depletion in PUA-producing diatoms is correlated to reduced hatching success, and can be compensated for by externally added single fatty acids.

\section{Introduction}

Plankton comprises all suspended organisms at the base of marine and freshwater food webs. Primary production by planktonic algae accounts for roughly half of the global carbon fixation, with diatoms being the most abundant algal group. ${ }^{[1]}$ Phytoplankton is mainly consumed by zooplankton species such as calanoid copepods, which themselves are the food source for higher trophic levels, such as fish. As a consequence, interactions between phytoplankton and zooplankton determine the trophic transfer and the energy flow in aquatic environments. Numerous factors in phytoplankton can influence the success of zooplankton, these include the structural properties of the algae, ${ }^{[2]}$ chemical defence ${ }^{[3,4]}$ and food quality ${ }^{[5,6]}$ Besides stoichiometric factors, such as the carbon-to-nitrogen ratio or the phosphorous availability, ${ }^{[7,8]}$ certain primary metabolites are involved in the regulation of trophic transfer. ${ }^{[9]}$ In this context, the fundamental impact of phytoplankton lipids and free fatty acids on predator success has been documented in many fresh water and marine studies. ${ }^{[5,10-12]}$ Predominantly polyunsaturated fatty acids but also steroids ${ }^{[13]}$ have been identified as key factors that influence the growth, survival and reproduction of predators. Copepods are retaining polyunsaturated fatty acids such as eicosapentaenoic acid (C20:5 $\omega-3$, EPA 1) and docosahexaenoic acid (C22:6 $\omega-3$, DHA) at all stages during development. ${ }^{[14]}$ Thus, the amount of EPA can determine the transfer efficiencies between primary pro- ducers and consumers. ${ }^{[10,11,15,16]}$ This is supported by the correlations that were found between the amount of EPA and other $\omega$-3-polyunsaturated fatty acids in the nutrition and growth of juvenile Daphnia galeata, ${ }^{[17]}$ or in the egg production and via-

[a] Dr. T. Wichard, Prof. Dr. G. Pohnert

Ecole Polytechnique Fédérale de Lausanne (EPFL)

Institute of Chemical Sciences and Engineering

1015 Lausanne (Switzerland)

[b] Prof. Dr. G. Pohnert

Current address: Institute for Inorganic and Analytical Chemistry

Department of Bioorganic Analytics, Friedrich-Schiller-Universität Jena Lessing Strasse 8, 07743 Jena (Germany)

Fax: $(+49)$ 3641-948172

E-mail:georg.pohnert@uni-jena.de

[c] Dr. T. Wichard

Max-Planck-Institute for Chemical Ecology Hans-Knöll-Strasse 8, 07745 Jena (Germany)

[d] A. Gerecht, Dr. M. Boersma, Prof. Dr. K. Wiltshire Alfred-Wegener-Institut

Kurpromenade, 27498 Helgoland (Germany)

[e] Dr. M. Boersma

GKSS Research Centre, Institute for Coastal Research 21502 Geesthacht (Germany)

[f] Dr. S. A. Poulet

Station Biologique de Roscoff, CNRS, INSU UPMC Paris VI, Unité Mer et Santé Roscoff 29682 (France) 
bility of herbivorous copepods. ${ }^{[6,18]}$ In all these investigations, the fatty acid content of the food algae was monitored by the direct determination of total fatty acids after hydrolysis of the algal lipids. While this method allows the determination of the actual fatty acid content of the food during the normal growth of a phytoplankton culture or in the field, it might not reflect the definite nutritional value of diets. Rather, processes that occur after cell disruption and during gut transfer would also have to be considered if the actual situation during the food uptake is concerned. $^{[3,19]}$ In the last years it has been documented that certain diatoms react rapidly with the release of the polyunsaturated aldehydes 4-8 (PUA) upon mechanical wounding (Scheme 1). ${ }^{[20,21]}$ This mechanism is discussed in the context of a defence mechanism which is activated during predator feeding and induces for example, decreased zooplankton egg-hatching success and offspring survival. $^{[22-24]}$ The polyunsaturated aldehydes 4-8 are biosynthetically derived from free polyunsaturated fatty acids ${ }^{[20,25]}$ that are released from phospho- and galactolipids after cell disruption (Scheme 1). ${ }^{[26,27]}$ The fatty acids are transformed by lipoxygenases, hydroperoxide lyases and halolyases into aldehydes upon cell disruption. ${ }^{[22,25]}$ Owing to the fatty acid degradation during cell breakage, it is possible that the diatom diet lacks essential fatty acids, and the copepods can no longer benefit from these PUFAs. Despite the onset of enzymatic transformations after the wounding of unicellular algae the impact of these processes on food quality parameters has not been considered until now. We show here that the effective content of polyunsaturated fatty acids might be dramatically overestimated if only total fatty acids are monitored in intact phytoplankton.

\section{Results and Discussion}

\section{Rapid fatty acid depletion upon cell disruption}

If an isolate of the diatom Thalassiosira rotula that is capable of producing the polyunsaturated aldehydes 4, 5, 7 and 8 is wounded, the amount of EPA, is rapidly depleted. Within a few minutes only ca. $30 \%$ of the initial EPA-content can be detected (Figure $1 \mathrm{~A})$. This fatty acid is the precursor of $(2 E, 4 E / Z)$ hepta-2,4-dienal 4, (2E,4E/Z,7Z)-deca-2,4,7-trienal 5 and $(5 Z, 8 E /$ $Z, 10 E)$-12-oxododeca-5,8,10-trienoic acid 6. ${ }^{[22,25]}$ Similar depletion kinetics were observed for other polyunsaturated fatty acids, such as $C 16: 3$ and $C 16: 4$, which are the precursors for (2E,4E/Z)-octa-2,4-dienal 7 and (2E,4E/Z,7Z)-octa-2,4,7-trienal
8. ${ }^{[28,29]}$ In contrast, saturated fatty acids, which are not involved in these lipoxygenase-mediated pathways, remained unaffected (Figure 1 A, Table 1). To verify if this fatty acid depletion is functionally linked to the production of unsaturated aldehydes, we conducted experiments to compare the fatty acid depletion of wounded Thalassiosira pseudonana, a diatom that is
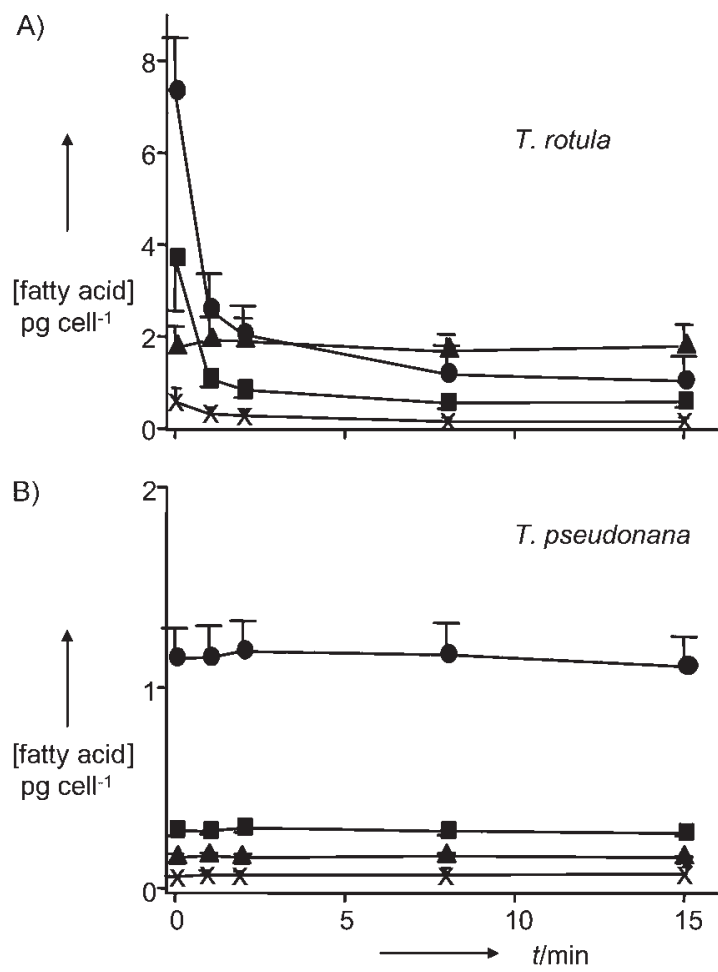

Figure 1. Time course of the depletion of different fatty acids in the polyunsaturated aldehyde producing T. rotula (top) and the non-producing T. pseudonana (below). $\mathbf{m}$ : EPA; $\bullet$ : sum of $C 16: 3 \omega-4$ and $C 16: 4 \omega-1 ; \mathbf{\Delta}: C 14: 0 ; \times$ : C22:6. Error bars indicate SD. 
known to lack this lipoxygenase pathway. Indeed, in this alga no significant changes in the level of PUFA were observed after wounding (Figure 1B, Table 1). In a broader survey, other PUA-releasing diatoms, such as Stephanopyxis turris and Skeletonema costatum showed wound-activated PUFA depletion as well. In contrast, Thalassiosira weisflogii and Rhizosolenia setigera, which do not produce any $\mathrm{PUA}^{[21]}$ exhibited no PUFA-depletion even after prolonged incubation subsequent to wounding (Table 1, Figure 2).

The high amount of fatty acid consumption cannot be entirely attributed to transformations to polyunsaturated aldehydes: only about $50 \%$ of the depletion of EPA in T. rotula can be explained by the production of the EPA-derived polyunsaturated aldehydes (2E,4E/Z)-hepta-2,4-dienal 4 and $(2 E, 4 E / Z, 7 Z)$ deca-2,4,7-trienal 5 (Figure 3). But kinetic experiments showed that the rates of fatty acid depletion and formation of the polyunsaturated aldehydes were very similar (Figure 3). Thus, it is likely that other mechanistically related lipoxygenase-mediated transformations to, for example, hydroxy- or oxoacids also consumed this fatty acid. ${ }^{[30,31]}$ This is supported by the observation, that polyunsaturated $\mathrm{C} 18$ and $\mathrm{C} 22$ fatty acids, which are potential lipoxygenase substrates but have not been linked to the formation of $\mathrm{PUA}^{[26,28]}$ were also depleted (Table 1). In the case of DHA $31-69 \%$ of the initial fatty acid is transformed by PUA producers (Table 1). In our survey, the rapid PUFA depletion is generally only found in diatoms that have the biosynthetic machinery required for the production of PUA. But certain specificity is observed if the fatty acid depletion of the PUA-producing T. rotula and S. costatum is compared with that of S. turris, which produces the oxo-acid 6 . While the former two species transform PUFAs with chain lengths of C16-C22 carbons, only C20 and C22 fatty acids are accepted as substrates for $S$. turris enzymes.

The fatty acid depletion by diatoms with active lipoxygenase(s) is highly efficient; in our experiments up to $69 \%$ of the unsaturated fatty acids were transformed within a few minutes after cell disruption. Previous investigations of the lipid content and composition of T. rotula and S. costatum indicated that the majority of the polyunsaturated fatty acids is stored in polar lipids, such as phospho- and galactolipids, while a smaller amount can be detected in the unpolar lipid fractions. ${ }^{[32,33]}$ Our results suggest that the involved fatty acids, which are bound to polar lipids might be nearly entirely used for further downstream reactions. Those polyunsaturated fatty acids that

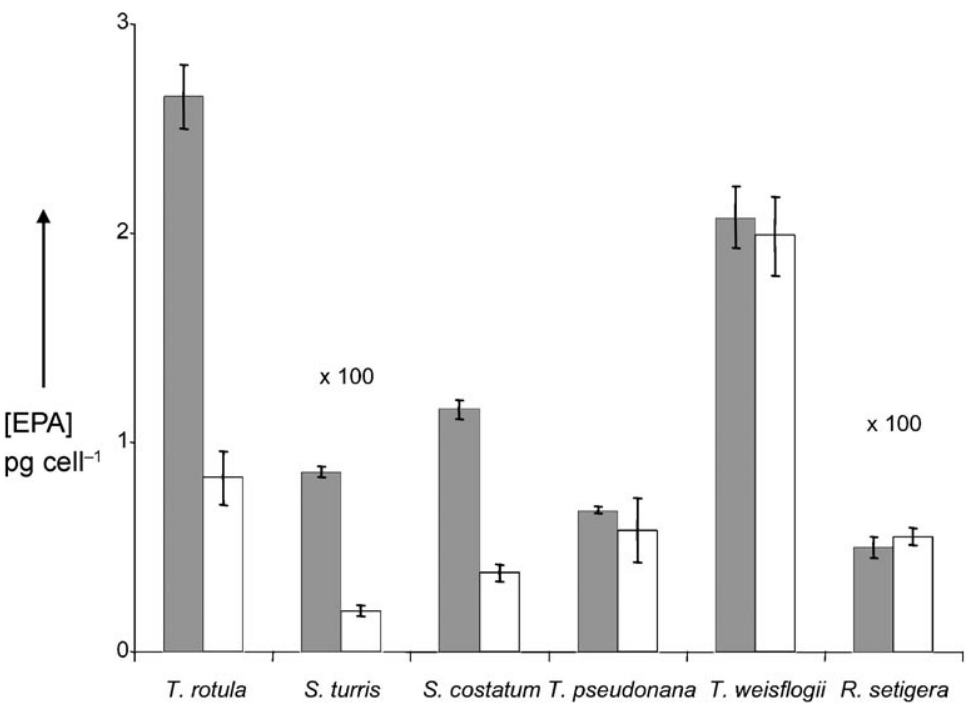

Figure 2. Depletion of eicosapentaenoic acid (EPA) after wounding of diatom cells. Grey bars: intact cells with enzymatic activity inhibited by acidifying before workup, white bars: 15 min after cell disruption. Error bars indicate SD.

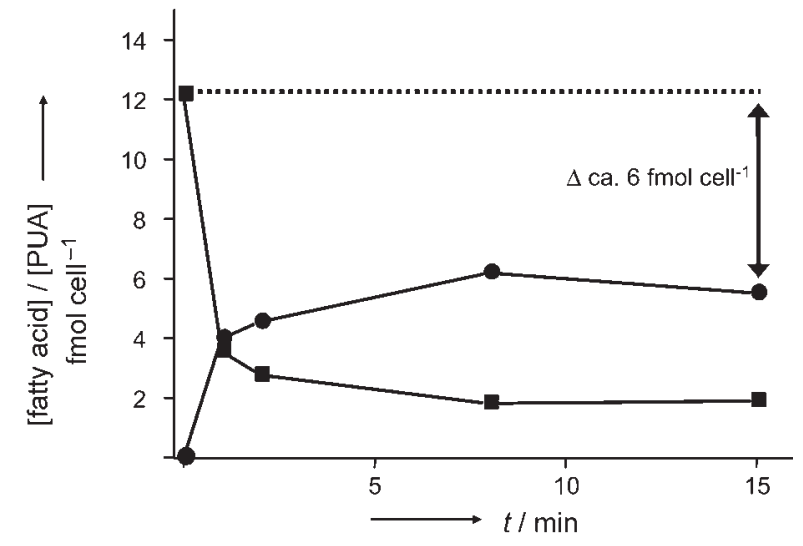

Figure 3. EPA depletion ( $\mathbf{\square}$ ) and formation of EPA-derived decatrienal and heptadienal ( $\bullet$ ) after wounding of $T$. rotula 
are stored in triacylglycerides, for example, are not released and transformed, ${ }^{[26]}$ and could account for the remaining PUFAs after wounding.

\section{Use of lipids and fatty acids by algae of different species}

Usually a multitude of different unicellular algal species and strains coexist at any given time in plankton. Since the feeding activity of the predators is not entirely selective towards specific algae, more or less random mixtures of different phytoplankton species will be ingested. All consumed species will contribute as a mixture to the food quality, but will also be disrupted simultaneously in the feeding organs of the predators. During this process, enzymes from different phytoplankton species might come into contact with lipids from other sources. Because the observed in vitro fatty acid depletion occurs fast and with remarkable efficiency, we wanted to verify if lipids from sources other than those of the producers of polyunsaturated aldehydes are also transformed. For verification, T. pseudonana, which does not produce PUA was homogeneously labelled with ${ }^{13} \mathrm{C}$. This alga was then mixed with $T$. rotula in a ratio of 10:1 and the mixture was subsequently damaged by sonication. Volatile polyunsaturated aldehydes were derivatised, extracted and submitted to GC-MS investigation. Evaluation of the mass spectra revealed that the resulting polyunsaturated aldehydes were significantly labelled (Figure 4), which proves that lipids from the lipoxygenase-containing algae as well as those from the other diatom species were readily transformed. When damaged T. rotula cells were administered to intact labelled T.pseudonana, only unlabelled PUAs were detected (data not shown); this indicates that only internal lipids of T. pseudonana are substrates for the T. rotula enzymes.

Since PUFAs are essential components of the food for copepods ${ }^{[6,18]}$ this result sheds new light on the impact of mixed species in the diets. Even a relatively small proportion of diatoms that are capable of producing polyunsaturated aldehydes might actively deplete the entire species-rich food of essential fatty acids. Moreover, because the total polyunsaturated aldehyde production can be increased by supplementation with external algal-derived lipids, the amount of these toxins that are released during the feeding process in the plankton has been underestimated because in most investigations only single species were considered in the chemical analyses. ${ }^{[34]}$ Interestingly, natural diatom assemblages with only one identified PUA-producing species ( $T$. rotula) release a significantly higher amount of PUA per diatom cell in phytoplankton than the isolated species in culture (Wichard et al. unpublished results and ref. [34]). This unusually high PUA production, which was suspected to be due to different growth conditions in nature and culture, might also be a result of the use of lipids from other algal sources in the natural phytoplankton samples; this could have artificially increased PUA levels.

\section{Lipase activity under physiological conditions}

The processes observed here depend on a close interaction between the predator and prey. The enzymatic transformations occur in the seawater, ${ }^{[34]}$ and thus most likely around the feeding organs of the predators and maybe even in the herbivore gut. To test if the mechanisms that were observed in the in vitro investigations can also play a role during the regular food uptake of herbivorous copepods, we treated the PUA-producing S. turris with the fluorogenic label 1,2-bis-(4,4-difluoro-5,7-dimethyl-4-bora-3a,4a-diaza-s-indacene-3-undecanoyl)-sn-glycero-3-phosphocholine. Only upon hydrolytic activity of phospholipase(s) are fluorescent fatty acids released from the lipid, which allows us to monitor the enzyme activity. ${ }^{[2]}$ If this fluorophore is incubated with intact diatoms, no enhanced phospholipase activity can be observed (Figure 5A), while wounded cells ${ }^{[26]}$ or cells that had been treated with commercially available phospholipase $A_{2}$ exhibit strong fluorescence, when excited with $488 \mathrm{~nm}$ (Figure 5B). If the cells that bear the fluorophore are fed to the copepod Calanus helgolandicus, pronounced phospholipase activity
Figure 4. Mass spectrum of the PFBO derivative of octadienal from wounded T. rotula A) and a mixture of wounded T. rotula and ${ }^{13} \mathrm{C}$-enriched T. pseudonana B) The cluster of ions between 320 and 327 can be attributed to labelled octadienal. 

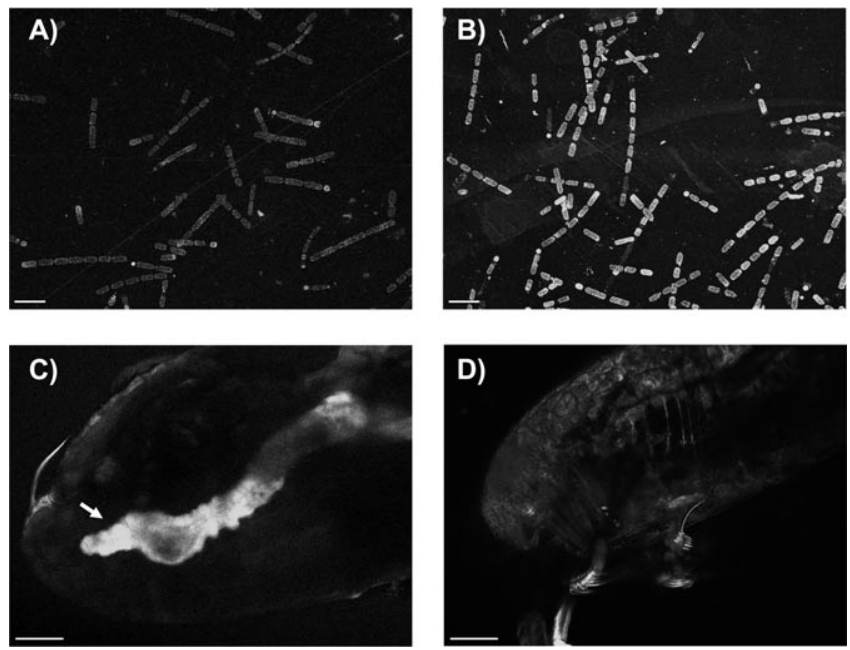

Figure 5. Detection of phospholipase activity in the gut of Calanus helgolandicus by using confocal microscopy. A) The diatom S. turris was incubated with bis-BODIPY PL and was subsequently treated with commercial available $P L A_{2}$ (B). C) Picture of the region of the foregut (arrow) of a C. helgolandicus copepod that was fed with bis-BODIPY PL-incubated S. turris. One optical slice is shown. D) Gut of a copepod which was kept in a bis-BODIPY PL-enriched medium as a control. To show the residual total fluorescence, the picture was processed by a stack of optical slices. Excitation wavelength (argon-ion laser) $488 \mathrm{~nm}$, scale bar: $100 \mu \mathrm{m}$ (for details see the Experimental Section).

in the foregut can be observed (Figure 5C). A control group of copepods that were treated with the label alone did not show any increased fluorescence in the gut (Figure 5D). This is in accordance with the finding that even if the copepod gut contains numerous digestive enzymes, a pronounced phospholipase activity was not identified as yet. ${ }^{[35]}$ In accordance with the nearly neutral $\mathrm{pH}$ in the copepod gut, ${ }^{[36]}$ the enzymes that were released from the damaged algae are still active in the foregut; they transform lipids and presumably deplete the polyunsaturated fatty acids of the entire food.

\section{Fatty acid supplementation}

When algal cells were supplemented externally with EPA, heptadienal and decatrienal production upon wounding increased significantly. This was also the case for decadienal production after the external addition of arachidonic acid (C20:4 $\omega-6$, ARA) (Figure 6A) ${ }^{[26]}$ As already indicated by the mixed diet experiments described above, the potential PUA-production of the cells is thus limited by the availability of the substrate fatty acids. Despite this increased PUA production, fatty acid supplementation could be adjusted so that an EPA content that exceeded that of intact cells was reached (Figure 6B). This allowed us to evaluate the combined effect of reduced food quality due to PUFA depletion, and increased potential toxicity due to increased PUA formation. Feeding the enriched algae to copepods resulted in increased tissue levels of EPA or ARA (Figure 6C, Table 2). These supplemented fatty acids were apparently incorporated, and further evaluation of the effects of manipulated fatty acid levels on reproductive parameters was thus possible.
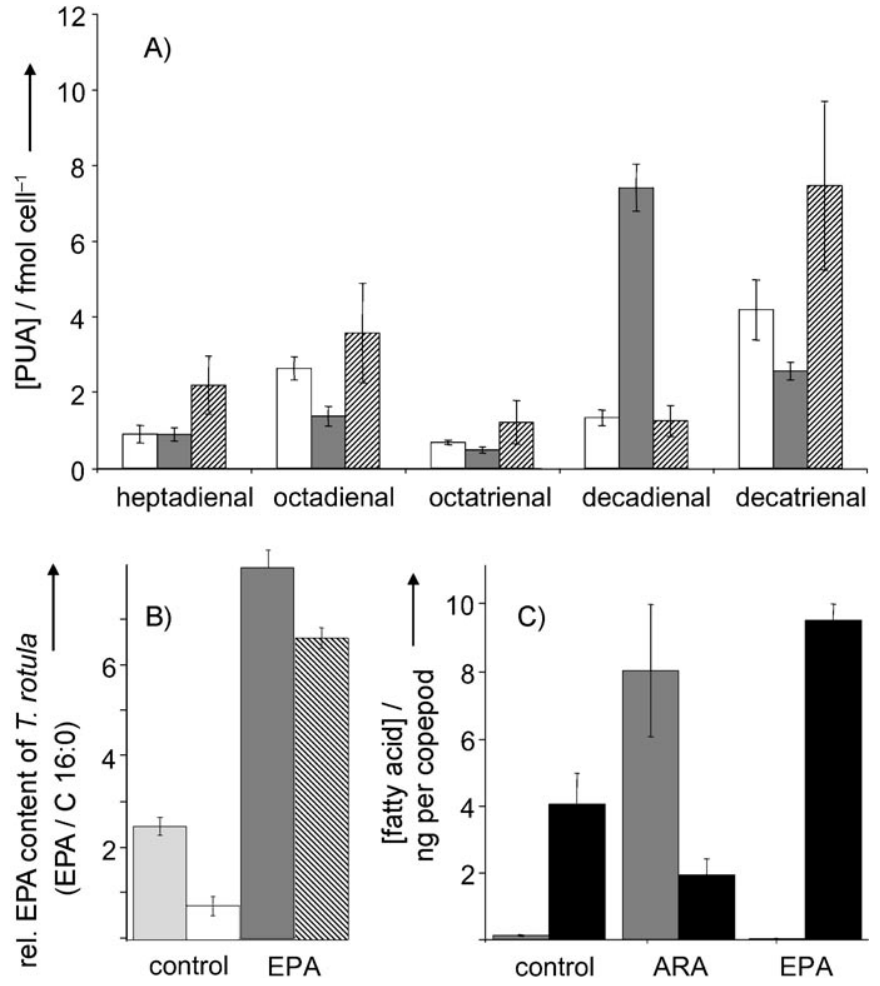

Figure 6. A) Changes in the amount of polyunsaturated aldehydes after treatment with arachidonic acid (grey bars) and eicosapentaenoic acid (hatched bars). The white bars show the production of PUA by a wounded T. rotula control. B) EPA content of intact (light grey bar), wounded (white bar), EPA-enriched (dark grey bar) and EPA-enriched wounded (hatched) T. rotula. C) Fatty acid content of copepod females reared on T. rotula (control: unenriched); on T. rotula supplied with arachidonic acid (ARA) and on $T$. rotula supplied with eicosapentaenoic acid (EPA). Grey bars represent the arachidonic acid level, black bars represent the EPA level.

\begin{tabular}{|c|c|c|c|c|}
\hline Treatment & $18: 3 \omega-3$ & $\begin{array}{l}20: 4 \omega-6 \\
(A R A)\end{array}$ & $\begin{array}{l}20: 5 \omega-3 \\
(E P A)\end{array}$ & $\begin{array}{l}22: 6 \omega-3- \\
(\mathrm{DHA})\end{array}$ \\
\hline T. rotula control & $0.48 \pm 0.18$ & $0.12 \pm 0.04$ & $4.0 \pm 1.6$ & $2.8 \pm 1.1$ \\
\hline T. rotula + ARA & $0.15 \pm 0.07$ & $8.0 \pm 3.4$ & $1.9 \pm 0.8$ & $2.6 \pm 1.2$ \\
\hline T. rotula + EPA & $0.13 \pm 0.01$ & 0.0 & $9.5 \pm 0.9$ & $2.3 \pm 0.4$ \\
\hline $\begin{array}{l}\text { Rhodomonas } \\
\text { sp. }\end{array}$ & $1.14 \pm 0.16$ & $0.04 \pm 0.03$ & $3.3 \pm 0.6$ & $5.7 \pm 1.1$ \\
\hline
\end{tabular}

Effect of dynamic metabolic transformations on the hatching success of Temora longicornis

To test the effect of EPA depletion on the hatching success of eggs produced by the copepod Temora longicornis, incubation experiments with EPA-enriched and nonenriched diatoms were performed. In these bioassays the PUA-producing species T. rotula (78 $\pm 30 \mathrm{ng}$ EPA (mg C) ${ }^{-1}$ ) and the non-producer T. weissflogii $\left(350 \pm 184 \mathrm{ng}\right.$ EPA $\left(\mathrm{mg} \mathrm{C}^{-1}\right)$ were compared. The hatching success of $T$. longicornis benefited from EPA supplementation of the $T$. rotula diet compared to animals that were reared on untreated T. rotula (Figure 7). A comparable increase in hatching success was not observed if $T$. weissflogii was sup- 

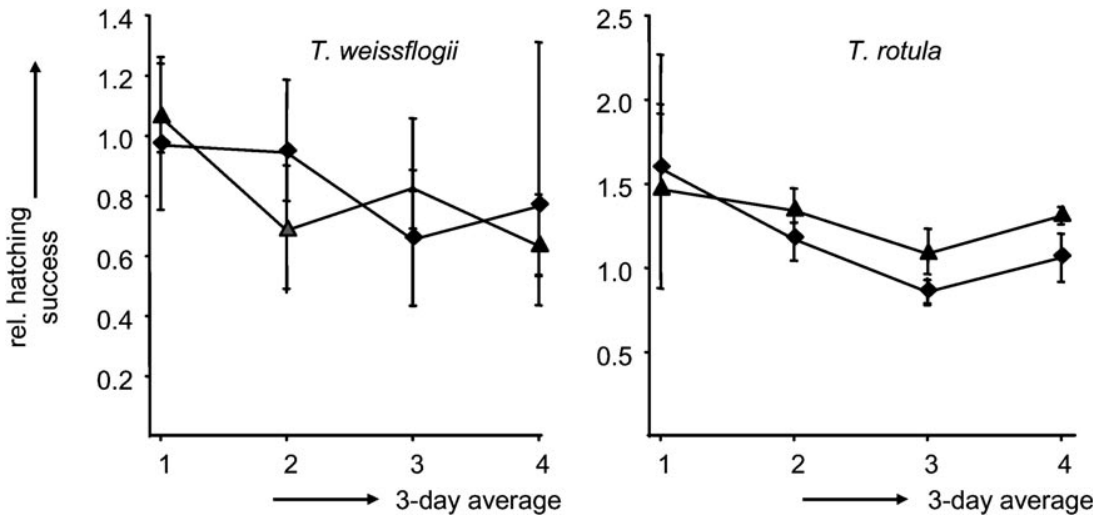

Figure 7. Left: Hatching success of eggs from T. longicornis fed with T. weissflogii ( $\bullet$ ) or T. weissflogii enriched with eicosapentaenoic acid ( $\mathbf{\Delta}$ ). Right: Hatching success of eggs from T. longicornis fed with T. rotula ( $\bullet$ ) or T. rotula enriched with eicosapentaenoic acid $(\mathbf{\Delta})$. The relative hatching success is calculated in relation to the hatching success in the control treatment where T. longicornis was fed Rhodomonas sp. as [\% hatching success treatment]/[\% hatching success Rhodomonas sp.]. The error bars represent maximum and minimum values.

general use of PUFAs as biomarkers in surveys of trophic transfer. In the biomarker approach, fatty acid profiles in the consumer and the feeding environment are compared to find potential similarities; this suggests a trophic connection. If certain fatty acids are destroyed during the feeding process, the likelihood increases that no relation will be found. In these cases, such surveys would not only have to include the fatty acid profile from algal cultures or field samples, but should also consider the effective PUFA levels in the food.

Our work also has strong im-

plemented with additional EPA and fed to the copepods (Figure 7). These results show that the negative effects of EPA depletion in T. rotula could be at least partly compensated for by enriching algal cells in this single fatty acid. This was true despite the concomitant increased production of PUA, which is considered to be the primary factor for the inhibition of hatching success. ${ }^{[23]}$ It is noteworthy that even in the untreated case, the hatching success with T. weissflogii as food was lower and more variable than with $T$. rotula. Thus, an overlaying algal species effect, which is even larger than the supplementation effect can be postulated. This is in agreement with the strong species dependence of hatching rates that has been observed in other laboratory experiments. ${ }^{[37]}$ Since mature females expend all of their energy sources on egg production ${ }^{[38]}$ it can be assumed that the decreased amounts of valuable unsaturated fatty acids due to the wound-activated transformations will be passed on to the eggs. Because EPA enrichment of the diet is immediately correlated to the increased EPA levels in the females, it could be concluded that a higher EPA transfer to the eggs might result in reproductive cells of higher quality. In contrast, the hatching success of $T$. weissflogii remained unaffected by EPA enrichment; this further supports the concept of nutritional deficiency caused by wound-activated fatty acid degradation in T. rotula, but not in the lipoxygenase-inactive T. weissflogii.

\section{Conclusions}

In the light of our findings, the PUFA content of diatoms and their related quality as food for herbivores has to be reconsidered. Dynamic processes that occur during food uptake and even in the copepod gut might alter the available levels of PUFA significantly due to lipid and fatty-acid-transforming enzymes. The determinant of this process is apparently a strong lipoxygenase-dependant production of oxylipins, which are found in several diatoms. ${ }^{[21,30,39]}$ Our finding that the fatty acid levels in food cells do not necessarily correspond to the effective fatty acids encountered in natural diets also questions the plications for the ongoing discussion about the defensive value of PUA. ${ }^{[40]}$ The aldehydes are considered to be the major line of defence by acting on fast proliferating reproductive cells in copepods. The copepod T.longicornis, however, showed a higher hatching success after supplementation of the food with EPA, even if the levels of the PUA decatrienal and heptadienal were simultaneously significantly increased; this contradicts the theory. Apparently, in this particular predator-prey system, reproductive success is influenced more strongly by the availability of EPA then by the toxic effects of the reactive polyunsaturated aldehydes. ${ }^{[23,24,41]}$ In this case, the produced aldehydes might instead be a by-product of the fatty acid depletion and not the direct causal factor of reproductive failure. This corresponds with the theory proposed by Jónasdóttir et al., ${ }^{[42]}$ who explain the deleterious effect of diatoms on copepod reproductive success by a nutritionally deficient diet. As in all laboratory studies, our investigation can only be seen as a case study that provides correlative evidence, and does not allow a general conclusion about diatomcopepod interactions. Indeed several observations of reproductive failure in laboratory and field experiments cannot be correlated with lipoxygenase activity in the herbivore diets ${ }^{[22,43]}$ (Wichard et al. unpublished results) and, thus, additional factors besides PUA toxicity and PUFA depletion are expected to be determinant in the complex predator-prey interactions in the plankton. The new aspect introduced here, which demonstrates the link between nutritious and deleterious effects of food should be considered in future comprehensive studies.

\section{Experimental Section}

Algal cultures and isotope enrichment: Diatoms were grown as batch cultures in artificial medium under a $14: 10 \mathrm{~h}$ light/dark regime with $30-40 \mu \mathrm{E} \mathrm{m}^{-2} \mathrm{~s}^{-1}$ light intensity. For further details about culture conditions see reference ${ }^{[21]]}$ T. rotula (CCMP 1647), T. pseudonana (CCMP 1335) and T. weisflogii (CCMP 1336) originated from the Provasoli-Guillard National Center for Culture of Marine Phytoplankton in West Boothbay Harbor (Maine, USA). S. costatum 
(RCC 75) was obtained from the Roscoff algae collection (Roscoff, France), and S.turris was provided by the culture collection of algae and protozoa in Oban, Scotland.

To obtain uniformly ${ }^{13} \mathrm{C}$-labelled T.pseudonana, we replaced the $\mathrm{NaHCO}_{3}$ in the medium by $0.2 \mathrm{gL}^{-1} \mathrm{NaH}^{13} \mathrm{CO}_{3} \cdot{ }^{[14]}$ Cultures were grown for 15 days until the fatty acids were enriched with ${ }^{13} \mathrm{C}$ (as verified by GC/MS of the total fatty acids). The cell morphology of each culture was checked with light microscopy prior to harvest. Cells were counted with the Neubauer improved chamber (Marienfeld, Germany).

Copepods: The calanoid copepod T. longicornis (Müller, 1792, North Sea) was used in the incubation experiments. Copepods were selected from field samples that were obtained from the Helgoland Reede, North Sea, Germany and were kept in culture for at least five generations. Cultures were kept in natural $0.45 \mu \mathrm{m}$-filtered sea water at $15^{\circ} \mathrm{C}$ on a $16: 8 \mathrm{~h}$ light-dark cycle. A daily diet of excess (>500 $\mathrm{g} \mathrm{CL}^{-1}$ ) Rhodomonas sp. and Oxyrrhis marina was provided. Cohorts of the same age were used in the experiments.

The calanoid copepod C. helgolandicus was used for monitoring the phospholipase $A_{2}$ activity in the gut. Copepods were sampled offshore Roscoff, North Brittany, Western English Channel, France. ${ }^{[44]}$

Total fatty acid analyses: Lipids and free fatty acids were transferred to the corresponding fatty acid methyl esters by treatment with acetyl chloride/methanol, followed by direct extraction into hexane according to Lepage and Roy. ${ }^{[45]}$

When the cultures reached the stationary growth phase, $2 \mathrm{~mL}$ of three independent cultured replicates were sampled. Each aliquot was centrifuged ( $15 \mathrm{~min}, 4000 \mathrm{~g}$, at $4{ }^{\circ} \mathrm{C}$ ) and the supernatant was discarded. After the addition of $\left[{ }^{2} \mathrm{H}_{27}\right]$ myristic acid as an internal standard ( $2 \mu \mathrm{L}$ of a $10 \mathrm{mg} \mathrm{mL}^{-1}$ solution in methanol) the sample was treated with the methylation mixture $(0.5 \mathrm{~mL}$ methanol/acetyl chloride, 20:1, v/v) and hexane $(0.3 \mathrm{~mL})$. The mixture was heated for $10 \mathrm{~min}$ at $100^{\circ} \mathrm{C}$ in pressure-resistant glass vials. After cooling in an ice bath, distilled water $(0.5 \mathrm{~mL})$ was added and the sample was vortexed for $1 \mathrm{~min}$. For fast phase separation, the sample was centrifuged. The removed hexane layer was dried over sodium sulfate and directly analysed on a Finnigan Trace GC-MS (Thermo Finnigan, CA, USA, electron impact energy of $70 \mathrm{eV}$ ) equipped with a EC- 5 capillary column $(15 \mathrm{~m} \times 0.25 \mathrm{~mm}$ internal diameter, $0.25 \mu \mathrm{m}$ film thickness, Alltech, USA). The temperature program was $60^{\circ} \mathrm{C}$ (1 $\mathrm{min}$ ), $30^{\circ} \mathrm{Cmin}^{-1}$ to $120^{\circ} \mathrm{C}, 5^{\circ} \mathrm{Cmin}^{-1}$ to $250^{\circ} \mathrm{C}$, and $20^{\circ} \mathrm{Cmin}^{-1}$ to $300^{\circ} \mathrm{C}$ ( $\left.2 \mathrm{~min}\right)$. The fatty acid methyl esters were identified by synthetic ${ }^{[29]}$ or commercially available standards or by mass spectroscopy (hexadecatrienoic acid).

For depletion experiments, the pellet that was obtained as described above was resuspended in seawater (giving a total of $50 \mu \mathrm{L}) .\left[{ }^{2} \mathrm{H}_{27}\right]$ myristic acid ( $2 \mu \mathrm{L}$ of $10 \mathrm{mg} \mathrm{mL}^{-1}$ in methanol) as an internal standard was added and the mixture treated with ultrasound for $15 \mathrm{~s}$ (Bandelin Sonicator, Germany). After cell disruption, the mixture was incubated at room temperature for the defined time spans of the depletion experiments. Then the methylation mixture (methanol/acetyl chloride, 20:1, v/v) and hexane $(0.3 \mathrm{~mL}$ ) were added and the samples were treated as described above.

The ions that were used for quantification were monitored in totalion mode according to Dodds et al. ${ }^{[46]}$ Due to differences in the response factors, separate calibrations were performed in triplicates with myristic acid (C14:0, $\left.y=0.0991, R^{2}=0.9998\right)$, hexadecatetraenoic acid (C16:4 $\left.\omega-1, y=0.0139, R^{2}=0.9957\right)$, oleic acid (C18:1 $\omega-9$, $\left.y=0.0707, R^{2}=0.9994\right)$, linoleic acid (C18:2 $\omega-6, y=0.0399, R^{2}=$
0.9990), $\gamma$-linolenic acid (C18:3 $\left.\omega-6, y=0.0290, R^{2}=0.9971\right)$, EPA $\left(y=0.0332, R^{2}=0.9977\right)$, ARA $\left(y=0.0309, R^{2}=0.9966\right)$ and DHA $(y=$ $0.0279, R^{2}=0.9937$ ). No calibration for $\mathrm{C} 16: 3$ was performed due to a lack of a synthetic standard. In this case the response factor of hexadecatrienoic acid was assumed to be similar to that of $\gamma$-linolenic acid.

Fatty acid analysis during bioassays: The fatty acids of algal and copepod (T. longicornis) samples that were obtained during the bioassays were extracted and analyzed according to the following procedure. A defined volume of algal culture $(50-500 \mathrm{~mL})$ was concentrated onto precombusted GF/C filters and transferred to a $5 \mathrm{~mL}$ test tube. Silicate and dichloromethane/methanol $(4 \mathrm{~mL}$ $\mathrm{CH}_{2} \mathrm{Cl}_{2} / \mathrm{MeOH}, 2: 1, v / v$, GC-grade, Merck) were added, as well as $10 \mu \mathrm{L}$ of an internal standard (C13:0 and C23:0 fatty acids, each $c=0.25 \mu \mathrm{g} \mu \mathrm{L}^{-1} \mathrm{MeOH}$ ). Algal samples were sonicated for $90 \mathrm{~min}$ and copepod samples were ground together with silicate with a metal pestle. Afterwards the samples were treated with $0.88 \%$ potassium chloride solution $(2 \mathrm{~mL})$ and the dichloromethane phase was separated. The organic phase was dried under a nitrogen stream and methanol/sulfuric acid $\left(3 \mathrm{~mL}, \mathrm{MeOH} / \mathrm{H}_{2} \mathrm{SO}_{4}, 97: 3, \mathrm{v} / \mathrm{v}\right.$, Merck) were added before incubation for one hour at $70^{\circ} \mathrm{C}$. After extracting twice with hexane $(2 \mathrm{~mL})$, the solvent was removed under a nitrogen stream, and the sample was taken up in hexane $(50 \mu \mathrm{L})$ before analysing as described above.

Determination of polyunsaturated aldehydes: Polyunsaturated aldehydes were determined by using GC/MS after derivatisation with 0 -(2,3,4,5,6-pentafluorobenzyl) hydroxylamine according to a previously described procedure. ${ }^{[34]}$

Monitoring of phospholipase activity in the Copepod gut: The fluorogenic substrate 1,2-bis-(4,4-difluoro-5,7-dimethyl-4-bora3a,4a-diaza-s-indacene-3-undecanoyl)-sn-glycero-3-phosphocholine ( $2 \mu \mathrm{L}$ from a $1 \mathrm{mg} \mathrm{mL}^{-1}$ stock solution in ethanol, Molecular Probes, Leiden, The Netherlands) was added to $1 \mathrm{~mL}$ of a concentrated culture of $10^{6}$ cells $\mathrm{ml}^{-1} \mathrm{~S}$. turris in the stationary growth phase. After 5 min incubation at room temperature, the impregnated cells were added to filtered seawater $(150 \mathrm{~mL})$ and fed to freshly isolated females ${ }^{[44]}$ of the copepod C. helgolandicus. After overnight feeding, the copepods were fixed in $4 \%$ paraformaldehyde, and the phospholipase activity was immediately monitored in the copepod gut by using an inverse confocal laser-scanning microscope (IX 70 Fluoview, Olympus Optical Co., Tokyo, Japan). The fluorogenic substrate was excited with an argon-krypton continuous laser at $488 \mathrm{~nm}$ (Omnichrome, Melles Griot Laser Group, Carlsbad, CA, USA) with $>535 \mathrm{~nm}$ emission. Analysis of the images was performed by using the Fluoview 2.0 software.

As a control, the females were starved for the same time length in filtered seawater that contained the fluorogenic substrate $(2 \mu \mathrm{L})$ alone and were monitored in the same manner. To ensure the impregnation efficiency of the diatoms with the fluorogenic substrate, commercially available phosholipase $A_{2}$ (ca. 100 units per $\mathrm{mL}$ ) from honey bee venom (Sigma, Deisenhofen, Germany) was added to seawater containing S. turris cells, and activity was immediately monitored by confocal microscopy.

Enrichment with single fatty acids: Algal cells were enriched with EPA or ARA in an overnight incubation according to a protocol modified from ref. [47]. Algal culture $(300 \mathrm{~mL})$ was incubated with BSA ( $25 \mathrm{~mL}$ of a $4 \mathrm{mg} \mathrm{mL}^{-1}$ solution of bovine serum albumin in water) and the fatty acid in question $\left(2 \mathrm{~mL}\right.$ of a $2.5 \mathrm{mg} \mathrm{mL}^{-1} \mathrm{FA}$ solution in ethanol) or in ethanol $(2 \mathrm{~mL})$ for the nonenriched treatment (control). The algal culture was incubated on a rotary shaker (KS501 digital, IKA, Germany) at $100 \mathrm{rpm}$ for $13 \mathrm{~h}$ (overnight). The 
algal culture was then concentrated through centrifugation and the supernatant was discarded. The pellet was washed twice with filtered seawater $(50 \mathrm{~mL})$ and then used to create the food suspension for the incubation experiments.

Bioassays: Methods for the incubation of copepods as well as measurements of hatching success were taken from the Zooplankton Methodology Manual. ${ }^{[48]}$

T. longicornis species were incubated on a plankton wheel $(0.5 \mathrm{rpm})$ with $10-15$ females and $1-2$ males per $500 \mathrm{~mL}$ bottle, at a carbon concentration of $500 \mu \mathrm{gL}^{-1}$. Two incubation experiments were performed, one with T. weissflogii and one with T. rotula. For both diatom species, copepods were incubated with unenriched algae and with algae that had been enriched in EPA. Rhodomonas $s p$. at $500 \mu \mathrm{g} \mathrm{CL}^{-1}$ was used in a control treatment. Eggs were counted every $24 \mathrm{~h}$ under a dissecting microscope and were fixed with EtOH ( $2 \mathrm{~mL}$ ) after $48 \mathrm{~h}$. Hatching success is given as the percentage of nauplii after $48 \mathrm{~h}$. The incubation experiments lasted 12 days and three-day averages were formed for evaluation.

\section{Acknowledgement}

TW and GP acknowledge the German Research Foundation (DFG) for funding.

Keywords: algae • fatty acids • food quality · lipids metabolism $\cdot$ plankton

[1] V. Smetacek, Protist 1999, 150, 25-32.

[2] C. E. Hamm, R. Merkel, O. Springer, P. Jurkojc, C. Maier, K. Prechtel, V. Smetacek, Nature 2003, 421, 841-843.

[3] G. Pohnert, Top. Curr. Chem. 2004, 239, 179-219.

[4] J. T. Turner, P. A. Tester, Limnol. Oceanogr. 1997, 42, 1203-1214.

[5] M. Ederington, G. McManus, H. Harvey, Limnol. Oceanogr. 1995, 40, $860-867$.

[6] K. E. Arendt, S. H. Jónasdóttir, P. J. Hansen, S. Gartner, Mar. Biol. 2005 $146,513-530$

[7] A. Mitra, K. J. Flynn, J. Plankton Res. 2005, 27, 393-399.

[8] T. R. Anderson, M. Boersma, D. Raubenheimer, Ecology 2004, 85, 1193 1202.

[9] T. R. Anderson, D. O. Hessen, J. Plankton Res. 1995, 17, 317-331.

[10] M. T. Brett, D. C. Müller-Navarra, Freshwater Biol. 1997, 38, 483-499.

[11] D. C. Müller-Navarra, M. T. Brett, A. M. Liston, C. R. Goldman, Nature 2000, 403, 74-77.

[12] C. Becker, M. Boersma, Limnol. Oceanogr. 2005, 50, 388-397.

[13] R. P. Hassett, Limnol. Oceanogr. 2004, 49, 488-494.

[14] M. Graeve, C. Albers, G. Kattner, J. Exp. Mar. Biol. Ecol. 2005, 317, 109125.

[15] A. J. Fraser, J. R. Sargent, J. C. Gamble, D. D. Seaton, Mar. Chem. 1989, 27, $1-18$.

[16] M. Boersma, Limnol. Oceanogr. 2000, 45, 1157-1161.

[17] E. von Elert, Limnol. Oceanogr. 2002, 47, 1764-1773.

[18] S. H. Jónasdóttir, Mar. Biol. 1994, 121, 67-81.

[19] G. V. Wolfe, Biol. Bull. 2000, 198, 225-244.

[20] G. Pohnert; Angew. Chem. 2000, 112, 4506-4508; Angew. Chem. Int. Ed. 2000, 39, 4352-4354.

[21] T. Wichard, S. A. Poulet, C. Halsband-Lenk, A. Albaina, R. Harris, D. Y. Liu, G. Pohnert, J. Chem. Ecol. 2005, 31, 949-958.

[22] G. Pohnert, ChemBioChem 2005, 6, 946-959.
[23] A. Miralto, G. Barone, G. Romano, S. A. Poulet, A. lanora, G. L. Russo, I. Buttino, G. Mazzarella, M. Laabir, M. Cabrini, M. G. Giacobbe, Nature 1999, 402, 173-176.

[24] A. Ianora, A. Miralto, S. A. Poulet, Y. Carotenuto, I. Buttino, G. Romano, R. Casotti, G. Pohnert, T. Wichard, L. Colucci-D'Amato, G. Terrazzano, V. Smetacek, Nature 2004, 429, 403-407.

[25] T. Wichard, G. Pohnert, J. Am. Chem. Soc. 2006, 128, 7114-7115.

[26] G. Pohnert, Plant Physiol. 2002, 129, 103-111.

[27] G. d'Ippolito, S. Tucci, A. Cutignano, G. Romano, G. Cimino, A. Miralto, A. Fontana, Biochim. Biophys. Acta 2004, 1686, 100-107.

[28] G. d'Ippolito, G. Romano, T. Caruso, A. Spinella, G. Cimino, A. Fontana, Org. Lett. 2003, 5, 885-887.

[29] G. Pohnert, S. Adolph, T. Wichard, Chem. Phys. Lipids 2004, 131, 159166.

[30] G. d'Ippolito, A. Cutignano, R. Briante, F. Febbraio, G. Cimino, A. Fontana, Org. Biomol. Chem. 2005, 3, 4065-4070.

[31] W. H. Gerwick, Biochim. Biophys. Acta 1994, 1211, 243-255.

[32] J. P. Berge, J. P. Gouygou, J. P. Dubacq, P. Durand, Phytochemistry 1995, 39, $1017-1021$.

[33] A. Cutignano, G. d'Ippolito, G. Romano, N. Lamari, G. Cimino, F. Febbraio, A. Fontana, ChemBioChem 2006, 7, 450-456.

[34] T. Wichard, S. A. Poulet, G. Pohnert, J. Chromatogr. B 2005, 814, $155-$ 161.

[35] "Digestive Enzymes and their Relation to Nutrition", P. Mayzaud in The Biological Chemistry of Marine Copepods, Clarendon, Oxford, 1986.

[36] D. W. Pond, R. P. Harris, C. Brownlee, Mar. Biol. 1995, 123, 75-79.

[37] S. H. Ban, C. Burns, J. Castel, Y. Chaudron, E. Christou, R. Escribano, S. F. Umani, S. Gasparini, F. G. Ruiz, M. Hoffmeyer, A. lanora, H. K. Kang, M. Laabir, A. Lacoste, A. Miralto, X. R. Ning, S. A. Poulet, V. Rodriguez, J. Runge, J. X. Shi, M. Starr, S. Uye, Y. J. Wang, Mar. Ecol. Prog. Ser. 1997, $157,287-293$.

[38] J. A. Runge, J. C. Roff in ICES Zooplankton Methodology Manual (Ed.: R. Harris), Academic Press, San Diego, 2000.

[39] G. d'Ippolito, A. Cutignano, S. Tucci, G. Romano, G. Cimino, A. Fontana, Phytochemistry 2006, 67, 314-322.

[40] G. A. Paffenhöfer, A. Ianora, A. Miralto, J. T. Turner, G. S. Kleppel, M. R. d'Alcala, R. Casotti, G. S. Caldwell, G. Pohnert, A. Fontana, D. Müller-Navarra, S. Jónasdóttir, V. Armbrust, U. Bamstedt, S. Ban, M. G. Bentley, M. Boersma, M. Bundy, I. Buttino, A. Calbet, F. Carlotti, Y. Carotenuto, G. d'Ippolito, B. Frost, C. Guisande, W. Lampert, R. F. Lee, S. Mazza, M. G. Mazzocchi, J. C. Nejstgaard, S. A. Poulet, G. Romano, V. Smetacek, S. Uye, S. Wakeham, S. Watson, T. Wichard, Mar. Ecol. Prog. Ser. 2005, 286, 293-305.

[41] G. S. Caldwell, P. J. W. Olive, M. G. Bentley, Aquat. Toxicol. 2002, 60, 123 137.

[42] S. H. Jónasdóttir, T. Kiørboe, K. W. Tang, M. St. John, A. W. Visser, E. Saiz, H. G. Dam, Mar. Ecol. Prog. Ser. 1998, 172, 305- 308.

[43] X. Irigoien, R. P. Harris, H. M. Verheye, P. Joly, J. Runge, M. Starr, D. Pond, R. Campbell, R. Shreeve, P. Ward, A. N. Smith, H. G. Dam, W. Peterson, V. Tirelli, M. Koski, T. Smith, D. Harbour, R. Davidson, Nature 2002, 419, $387-389$.

[44] S. A. Poulet, T. Wichard, J. B. Ledoux, B. Lebreton, J. Marchetti, C. Dancie, D. Bonnet, A. Cueff, P. Morin, G. Pohnert, Mar. Ecol. Prog. Ser. 2006, 308, 129- 142.

[45] G. Lepage, C. C. Roy, J. Lipid Res. 1984, 25, 1391-1396.

[46] E. D. Dodds, M. R. McCoy, L. D. Rea, J. M. Kennish, Lipids 2005, 40, 420427.

[47] E. von Elert, Limnol. Oceanogr. 2002, 47, 1764- 1773.

[48] R. P. Harris, ICES Zooplankton Methodology Manual, Academic Press, San Diego, 2000.

Received: February 2, 2007

Published online on $\mathbf{\square}$ पI, 2007 


\section{FULL PAPERS}

You are what you eat? The quality of food from marine zooplankton cannot necessarily be deduced from the biochemical parameters of the algae that they graze on. Dynamic processes, such as a rapid transformation of essential polyunsaturated fatty acids can occur even in the gut of the animals (picture) thereby reducing the quality of the food.

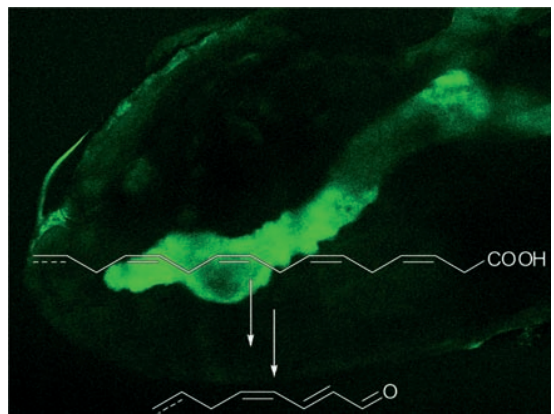

T. Wichard, A. Gerecht, M. Boersma, S. A. Poulet, K. Wiltshire, G. Pohnert*

Lipid and Fatty Acid Composition of Diatoms Revisited: Rapid WoundActivated Change of Food Quality Parameters Influences Herbivorous Copepod Reproductive Success 